\title{
Research Paper on Student Information System
}

\author{
Pragun Agarwal, Anubhav Joshi, Bharat Bhushan Naib
}

\begin{abstract}
With the help of Student Information System (SIS), student information can be stored and maintenance can be done. It is useful for educational institutions to maintain the records of students. The storage and management of information regarding a students'academics is crucial in any institution. This system can be useful for all types of details, academic reports, institutional details, curriculum, and other resource as well. Student Information System software is very essential nowadays for all the educational institutions to store the information of students. For storing the student data, the institutions are spending a lot of money on paper, files, and other stationary stuffs including pens/pencil etc or some institutions are purchasing expensive systems to do this stuff. But here we are just creating software for the similar work it can save a lot of expenditure of an institution and also it will save use of papers which is ultimately beneficial for our environment also. This system is very useful to sort and search student records because sorting and searching in file system is time consuming also difficult to conduct manually. This software was developed in such a way that it remains to be user centric and easily understandable and usable by the user. The software is fully functional and tested over several testing techniques available and the software is functioning smoothly.

Keywords: Admin Login, Student Login, Add Student, View Student, Registration, Update Profile
\end{abstract}

\section{INTRODUCTION}

The main idea behind developing a web based software to store and maintain student and academic records is to develop a cost effective system and to create a environment friendly way. The crucial information related to a student is only accessible to authorized persons on this software. The system is equipped with several security aspects likeuser authentication, and it will only show necessary details. It is very safe software because to get access to any information one need to login in the portal and login will be provided to authorized people only whereas in file systems, data security very less as compared to this system. When a student gets

Manuscript received on April 06, 2021.

Revised Manuscript received on April 13, 2021.

Manuscript published on April 30, 2021.

* Correspondence Author

Pragun Agarwal*, Student, Department of School of Computer Science and Engineering, Galgotias University, Greater Noida, India Email -agarwalpragun909@gmail.com

Anubhav Joshi, Student, Department of School of Computer Science and Engineering, Galgotias University, Greater Noida, India Email- anubhavjoshi125@gmail.com

Dr. Bharat Bhushan Naib, Assistant Professor, Department of School of Computer Science and Engineering, Galgotias University Greater Noida, India bharat.bhushan@galgotiasuniversity.edu.in

(C) The Authors. Published by Blue Eyes Intelligence Engineering and Sciences Publication (BEIESP). This is an open access article under the CC BY-NC-ND license (http://creativecommons.org/licenses/by-nc-nd/4.0/) admission in the institution, he/she will be registered on the portal and will be provided with a login and password. Student can view his/her own record only on this portal. As discussed earlier, this software is very cost effective eco-friendly as it eliminates paper work, also it safe to use in an organization for the faculty. Also, the modern world demands less paper work and more digital work in order to make operations easy and safe. This software also eliminates the chances of data theft and data loss. Hence, in short the software is better in all aspects.

\section{EASE OF USE}

This software is very easy to use and this is developed in a very user friendly way. The database stores only required information and user does not need to think of data security at all. The user only needs a PC/ Desktop and a stable internet connection to use the software. Also, the software saves a lot of time for various operations as compared to old traditional file system. Thus, we can conclude that it is quite easy to operate.

\section{METHODS AND TECHNIQUES USED}

The method to successful development of this software includes- designing, development and testing part. The design of web pages for different modules are carried out by using HTML, CSS \& JS. The development of web pages is done in such a way that the user can use it in quite efficient manner. The tools used for development of user interface include "Notepad++", and Eclipse. The software also includes various registration forms in order to get user registered. At the backend, which is generally known as developer module, the language use to develop the software is Advanced Java \& mainly Java Servlet are used to make the operations smooth. Now main part is about database where all the data will be stored and retrieved, the database used in the software is MySQL database in order to make efficient working of database. This is translational from a user based document to a data oriented programmers. In order to make it possible, this provides the procedural details necessary for implementation. In order to understand the development and operation procedure of this software we initially created a Flowchart which ultimately pointed out every scope and possibility of success and failure of the software. Thus, the system which we develop is reliable, easy to use and its maintenance costs is also very less. The software is developed in such a way that it eliminates all the drawbacks of old traditional files/paper based documents. The Student Information software is useful as here paper work is nil and user can store the data more efficiently and securely. The methodology carried out in this software development

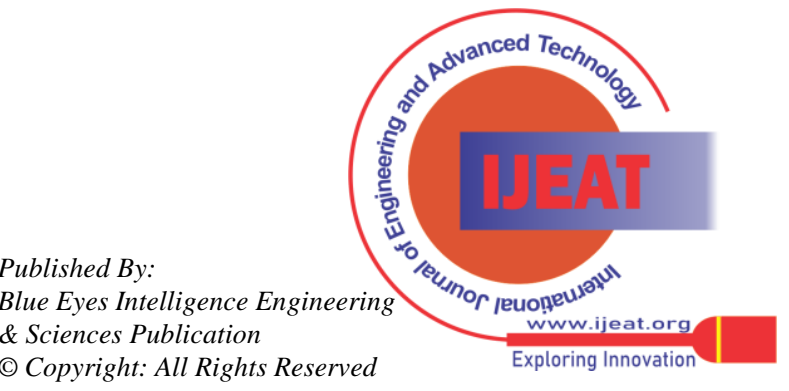


process is very systematically done in order to obtain smooth operation of the software. A flow chart diagram shows the various steps of the development process.

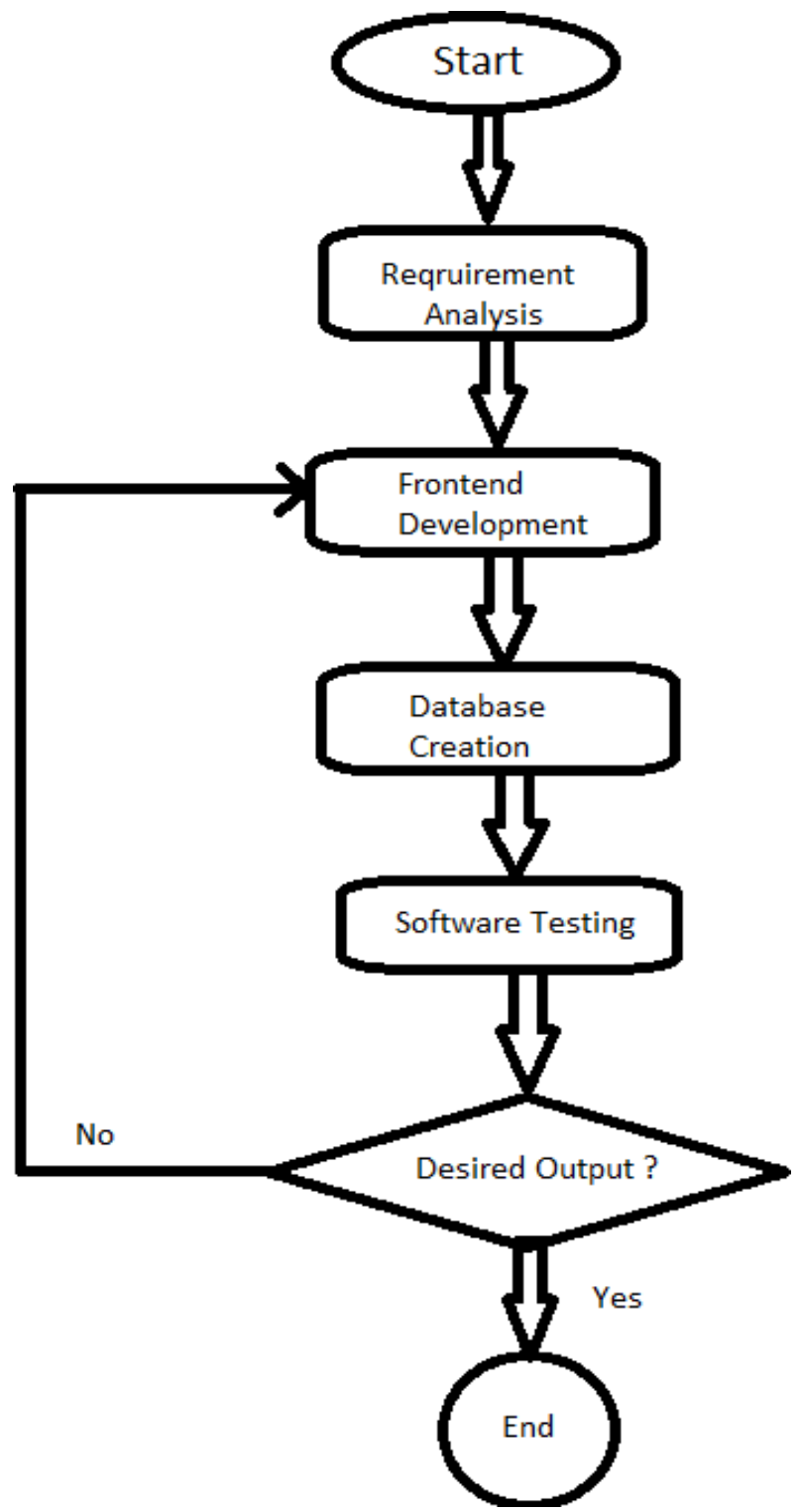

IV. TECHNICAL DETAILS

Main infrastructure includes a simple desktop/ laptop/PC having basic \& minimal system configuration to operate and for building a web based application we use Eclipse IDE installed with JDK and we use swing API's for building a layout.

\section{A. Eclipse IDE:}

Eclipse is an integrated development environment (IDE) used to develop various projects and applications by help of computer Programming languages. It is very general in use and easily understandable by the developer. Eclipse is written mainly in Java programming language and it is generally used is in developing Java applications.An extension of the Eclipse development platform is the Web Tools Platform (WTP), which have tools for developing both the Web and Java Enterprise Edition applications commonly known as JEE applications. For Several varieties of programming languages and built-in applications, the WTP includes source and graphical editors to simplify development, and it have several
APIs in order to facilitate the deployment, and to test the functioning of apps as well. In order to develop the Student Information System smoothly, we have used Eclipse in front end and in backend development as well to made the maintenance easy. For every module in this project, there is a separate .html file containing user interface code for that respective module. The best part of the Eclipse IDE is that we can programming language on this IDE for we executed Java or mainly the servlet codes.

\section{B. Java:}

Java is an advanced object-oriented programming language and is designed and created in such a way that the developer or the user will have as few implementation dependencies as possible.Java is both, general purpose programming language and also it is an advance programming language which is significantly in use this days to develop various object based applications. The reason, Java is widely in use is because Java supports WORA means Write Once and Run Anywhere, just user need to have JVM for the operating system he/she is going to run code on. In the software, advanced Java concepts are used for exampleServlet. The reason Java is used in the software system is because it is easy to use and also anyone with sounding knowledge of programming can understand the code. One more reason is the debugging is quite smooth in Java as compared to other high level cum object-oriented programming language. The Student Information system was developed purely on Java as the backend language since the entire front end and backend development is done on Eclipse, \& Java code runs faster on Eclipse IDE.

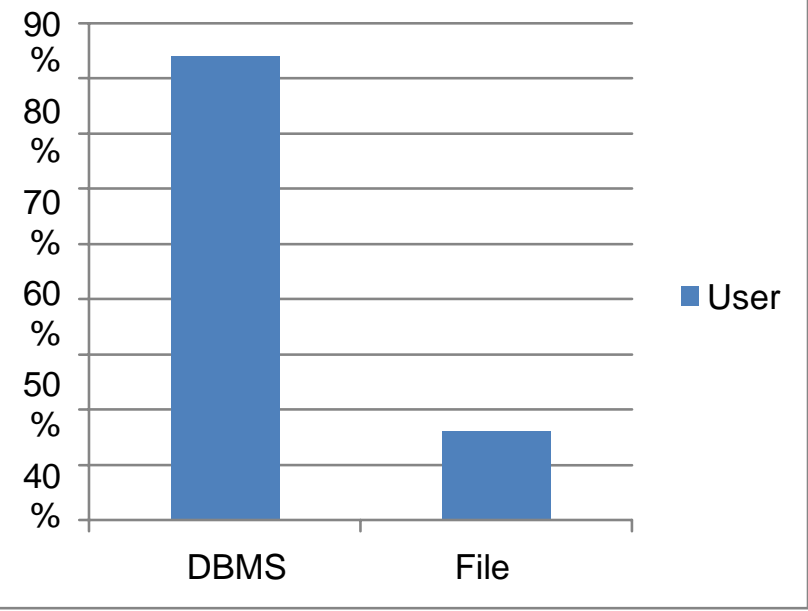

The set of extensible GUI Components which simply relax the life of a developer to create or develop Java based Front End Applications is widely known as Swing API which is useful to create web based software like Student Information System.

\section{MySQL Database:}

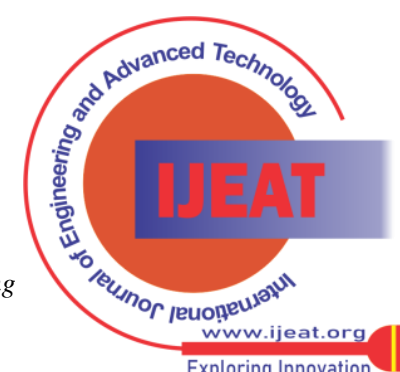
Exploring Innovation 
MySQL is a smooth \& efficient database to store any form of data from the user. MySQL database is a general purpose database which mainly stores and retrieves the data when needed. We used MySQL database in the Student Information System because it is quite easy to use and the database is tested several times in order to provide best experience to the user.In the Student Information System, the user give input related to particular fields asked from him and that input got stored at the backend in this MySQL database. The database is far better than the old way of storing information in the file system. Here in case of database, we are ensuring the security, authenticity and integrity of the information of user. While in old file systems we can't ensure anything among the above mentioned characteristics. Also, there is always a possibility of data loss or of data theft in file system. But by creating SIS and using MySQL database, we can eliminate the chance of data theft and data loss also. The popularity of Database to store and retrieve data can be seen clearly as DBMS cloud service providers are earning billions of USD every year for providing database services to its users. Graph representing survey report for preference between DBMS and File Management System. The below survey was carried out among 25 people out of them 21 people choose Database Management System to store their data in the database which amounts to be $84 \%$ users and 4 people chose File System to store their data in a database which amounts to be $16 \%$ of the total users Hence we can conclude that database is first choice of majority of the users to store their information.

\section{CREATION OF USER INTERFACE/FRONTEND DEVELOPMENT}

The front end development is the part of the software development process where the user interface was developed. The front end part consisted of several modules including the student login, student sign up form, faculty login, faculty sign up form, admin login module etc. The sign up page is a form where the user can register himself/ herself to the software. Once the user fill all the necessary fields and click signup button, the user will see a acknowledgement message that registration is successful. Similarly, on the login page user, need to login with his/her email id and the password, which was created at the time of sign up to the software. User needs to put correct id and password as only authentic user can login to the page. This authentication feature makes the Student Information System more secure and reliable.

\section{DATABASE CREATION}

Database Creation is one of the most important part of the development process of this system because all the details would be saved here and will be retrieved from the database. In this system, we have developed database for student, faculty and admin respectively. The database is safe and secure as the chances of data theft and data loss is highly eliminated. The database part of this software is tested several times and is safe to use and also it is smoothly working.

\section{SOFTWARE TESTING}

The software testing part is last and the most important process of this software. After completing the development of all the modules of user interface and the database the software testing was done. The testing of each module was done several times with different credentials to ensure that the user interface is working fine and user won't be affected in any way after using the software. After that, the database was checked in order to ensure smooth storage and retrieval of the information by each of the user. Thus Student Information System was thoroughly checked several times and we found it working fine and smooth.

\section{RESULT}

The software was developed after implementing its prototype to ensure that its prototype is working and hence the result came in our favour thus the development was carried out and after testing the Software it was found that the goals are achieved.

\section{CONCLUSION}

In this paper we are concluding that our goals and objectives are achieved successfully and everything that was expected from this software system is working fine and operations are smooth in this software. Thus, it is ready to use in any educational institute although hosting of the software on web portal is remaining. The software is a web based software product and it is functional on several browsers like Chrome, Internet explorer etc. The software was developed on a windows operating system and is working completely fine. Thus, here we conclude that the development of Student Information System software is completed and it is tested several times.

\section{ACKNOWLEDGEMENT}

We are grateful towards School of Computing Science and Engineering, Galgotias University, Greater Noida to provide us the Lab facility to carried out this research and development of the Student Information System.We are also grateful towards sir, Dr. Bharat Bhushan Naib, Faculty of School of Computing Science and Engineering, Galgotias University to help us during various phases of this project and to help us to carried out the research. His vast experience in research \& development and guidance in writing this research paper helped us to achieve this task successfully.

\section{REFERENCES}

1. Rick Dobson, Programming Microsoft Access 1999 and 2000.

2. G. Steven, Ed.D. Tuthill and Susan T. Leavy, Knowledge Based Systems, 1991

3. M.A. Norasiah and A. Norhayati. "Intelligent student information system". 4th International conference on telecommunication technology proceedings, Shah Alam, Malaysia, 0-7803-7773-7/03 2003 IEEE.

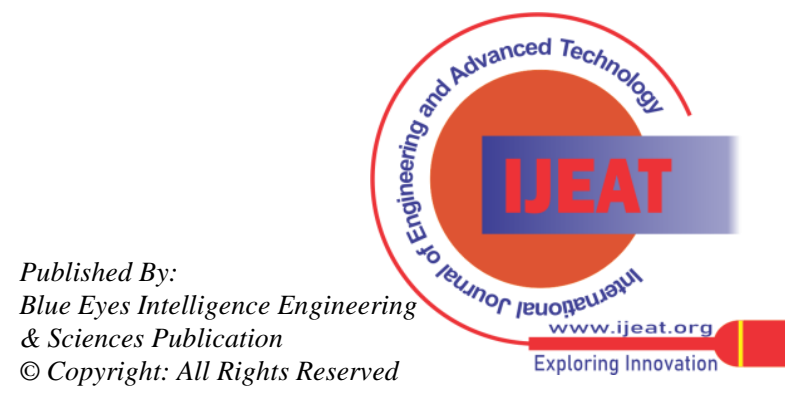


4. 4.S.R.Bharamagoudar, Geeta R.B. and S.G.Totad, "Web Based Student Information Management System", Andhra Pradesh, vol. 2, pp. 2342-2348, june 2013.

\section{AUTHORS PROFILE}

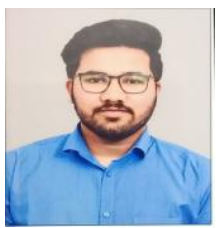

Anubhav Joshi, is a final year student, pursuing Bachelor of Technology with specialization in Computer Science and Engineering at Galgotias University, Greater Noida. He is working on his final year major titled "Student Information System" web based software, under the guidance of Dr. Bharat Bhushan Naib, Professor, Galgotias University. He will be an Engineering graduate by June 2021. He has coauthored 2 research papers in the field of computer science in a short span of about 4 years. Currently, he is working in Cognizant Technology Solutions as a Programmer Analyst Trainee. He has sounding knowledge in various programming languages like- Java, Python, $\mathrm{C}$ and $\mathrm{C}++$. Apart from programming languages he has good work experience in frontend development and he has developed several web based software. He worked in TechCiti Technologies Private Limited as a Software Developer Intern where he worked on several projects for the company, Lead his team and also developed several web based software applications. He was awarded $1^{\text {st }}$ rank in the district in the International English Olympiad organized by British Council. He has achieved several awards and certifications in various fields in university as well as in Inter-School competitions. Email: anubhavjoshi125@gmail.com

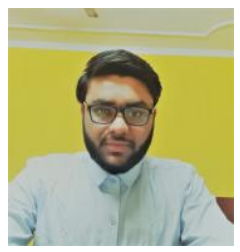

Pragun Agarwal, is a java enthusiast, he is an aspiring learner who has the willingness to learn. $\mathrm{He}$ is keen on learning cutting-edge technologies with hands-on experience. He is currently pursuing his bachelor's degree in Computer Science and Engineering from Galgotias University, Greater Noida. He has contributed to many projects with expertise in Java, problem-solving and analytical skills. He enjoys early responsibility, challenges, and exposure to various business practices across a range of verticles. He is very passionate to work in teams and trying to achieve web singularity. Email: agarwalpragun909@gmail.com

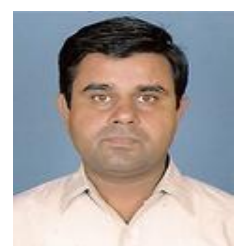

Dr. Bharat Bhushan Naib, has over 11 years of teaching and professional experience. He awarded his Ph.D. in Computer Science from Mewar University, Chittorgarh Rajasthan, is a research scholar and educator. He has published more than 10 research papers in journals of repute. He is presently serving as an Assistant Professor at Galgotias University, Greater Noida. He has expertise in WSN, Computer Networks. He Won a Consolation Prize in Science Fair in Class X for the project on 'Automatic Staircase Light'. He has chaired, participated in and presented at conferences and seminars in India and across the world. Apart from academic pursuits, he has shouldered many administrative responsibilities in various capacities. His research has pioneered developments in ensemble learning, outlier detection and Health care. Email: bharat.bhushan@galgotiasuniversity.edu.in

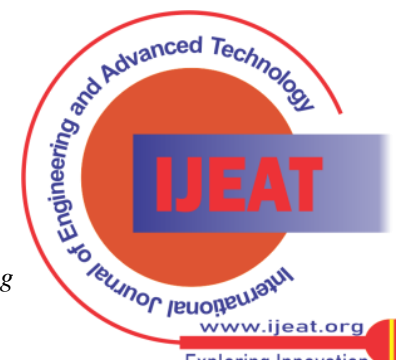

